\title{
Bacterial Infections in Unusual Sites in the Setting of Poor Glycaemic Control - Case Reports
}

\author{
Authors \\ Nkpozi MO'* ${ }^{*}$, Uche $\mathrm{CL}^{2}$
}

${ }^{1}$ Department of Medicine, Abia State University Teaching Hospital (ABSUTH), Aba, Abia State, Nigeria ${ }^{2}$ Department of Haematology and Blood transfusion, Abia State University Teaching Hospital (ABSUTH), Aba, Abia State, Nigeria

*Corresponding Author

\section{Dr MO Nkpozi}

Department of Internal Medicine, Abia State University Teaching Hospital (ABSUTH),

Aba, Abia State, Nigeria

Email: marcelnkpozi@gmail.com, GSM: +2348058525899.

\begin{abstract}
People living with diabetes are prone to bacterial infections; this susceptibility occurs because diabetes mellitus (DM) is associated with atherosclerotic vascular disease, sensory dysfunction and hyperglycaemia. Skin surface over the foot is, particularly, at risk, leading to foot ulcer.

The objective of this report is to draw attention to bacterial infections at unusual sites and their sequelae in persons living with diabetes with poor glycaemic control. Two such cases were seen and managed at different times at Abia State University Teaching Hospital, (ABSUTH), Aba, Nigeria. One who had a huge back abscess was successfully managed while the second person with DKA precipitated by acute fulminant cholecystitis did not make it. A back abscess in a patient with DM is either underreported in Nigeria or rare.

In conclusion, surgical interventions (incision and drainage (I \&D), debridement and serial wound dressings or cholecystectomy), antibacterial therapy and optimal glycemic control with insulin are necessary to ensure a favourable outcome.
\end{abstract}

Keywords: diabetes mellitus, bacterial infections, unusual infection sites, back abscess, fulminant cholecystitis.

\section{Background}

Diabetes mellitus (DM) is a leading cause of death worldwide and occurs in an epidemic proportion $\mathrm{i}$ $\mathrm{n}$ the developing countries ${ }^{1,2}$. The prevalence of $\mathrm{D}$ $\mathrm{M}$ is on the increase ${ }^{3}$, moreso, in sub saharan Afri cans $^{4}$ due to ageing of the population, improving $\mathrm{s}$ urvival of people living with diabetes, obesity, in creased urbanization and westernization, dietary c hanges and physical inactivity.
Complications of DM can be acute or chronic ${ }^{5}$. Hyperglycaemic emergencies constitute one of the acute metabolic complications of DM in which bacterial infection is a recognized precipitant. In a tertiary hospital based study in North West ${ }^{6}$, Nigeria, sepsis (30.9\%), HHS (14.2\%), DKA (7.4\%), diabetic foot ulcers (7.4\%) and cerebrovascular accidents (stroke) were the main indications for hospital admissions. 
In diabetic patients, skin and soft tissue infections can be associated with complications such as abscess, gangrene, osteomyelitis, bacteremia and sepsis $^{7-10}$. The most common sites of infections in diabetic patients are the skin and the urinary tract.

Diabetes mellitus increases susceptibility to various types of infection. Infections may precipitate metabolic derangements such as diabetic ketoacidosis (DKA), and conversely, the metabolic derangements of diabetes may facilitate infections. Severe bacterial infection occurs in patients with poorly controlled diabetes, especially those with diabetic ketoacidosis. Severe, fulminating infection of the gallbladder especially with gas-forming organisms (emphysematous cholecystitis) is more common in diabetic patients than the general population.

Reasons why diabetic patients are at increased risk for bacterial infections include impaired phagocytic mechanisms arising from defects in leukocyte chemotaxis, adherence and intracellular bacterial killing especially in the presence of hyperglycemia and diabetic acidosis. These are easily reversed when blood glucose and PH levels return to normal. In vitro evidence suggests a blood glucose concentration of $200 \mathrm{mg} / \mathrm{dl}$ as a possible threshold above which hyperglycaemia impair humoral function ${ }^{11}$

Published reports of back abscess at the level of the thoracic spine in a patient living with diabetes who had poor glycemic control is rare or underreported. Similarly, DKA precipitated by fulminant cholecystitis is not common in medical literature, hence, we decided to report the two cases.

\section{Case 1}

Mr E.E, a 58 year old trader on clothing materials, has been living with diabetes for 6 years. He presented to the Diabetes clinic with general body weakness, polyuria, pain in the upper back area and fever all of one week duration. He gave no history of cough, pleuritic chest pain, orthopnea or paroxysmal nocturnal dyspnea, exertional dyspnea, facial or leg swelling. Prior to presentation, he has been on lifestyles modifications, metformin and glibenclamide with poor adherence to clinic follow up.

Examination showed a middle aged man who was febrile (temperature 37.8 degrees centigrade), pale, not dehydrated and had no pitting pedal oedema. Systemic examination revealed a mass on the 1 - 2 thoracic spine area which measured $6 \times 3.5 \mathrm{~cm}$, tender, fluctuant at the centre with differential warmth. His other systems (cardiovascular, chest, abdomen and central nervous system) were essentially normal.

His random blood glucose at presentation was $239 \mathrm{mg} / \mathrm{dl}, \mathrm{HbA} 1 \mathrm{c} 12.5 \%$, full blood count showed a PCV $32 \%$, wbc $13.5 \times 10^{9} / \mathrm{L}$, neutrophil $83 \%$, lymphocytes $15 \%$, eosinophils $2 \%$, ESR $54 \mathrm{~mm} /$ 1 st hour, had normal kidney functions and chest radiograph. Incision and drainage of the back abscess yielded more than $150 \mathrm{ml}$ of milk coloured purulent material culture of which yielded heavy growth of staphylococcus aureus sensitive to ciprofloxacin.

He was placed on intravenous ciprofloxacin 200mg 12 hourly for 10 days, subcutaneous soluble insulin administered three times per day and surgical intervention involving incision and drainage, wound debridement and serial wound dressings. He was discharged home 4 weeks later when the wound was almost completely healed and the glycemic control was good.

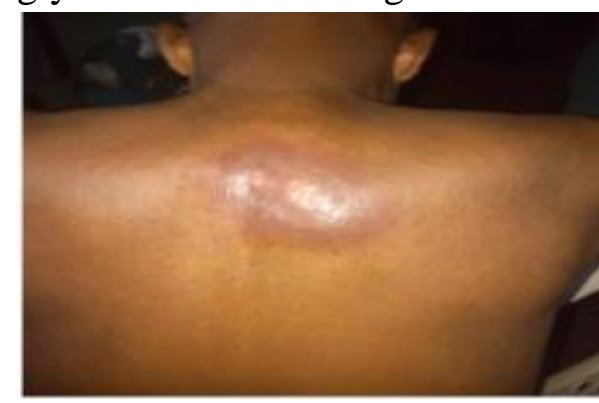

Figure 1: at presentation before I \&D.

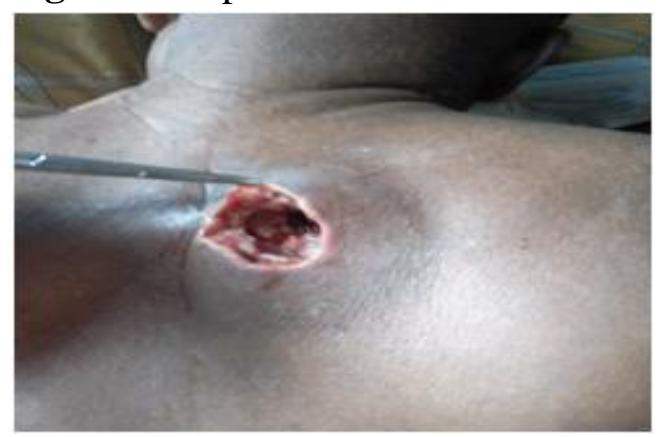

Figure 2: After I\&D and debridement 


\section{Case 2}

Mr J.O, a 63 year old leather bag trader, not previously known to have diabetes or hypertension, presented at the Accident and Emergency unit of ABSUTH, Aba with 3 days history of severe abdominal pain which was worse at the right upper abdomen. He vomited once prior to presentation. He gave no history of jaundice, change in bowel habit or cough.

Examination showed an acutely ill middle aged man, conscious but drowsy, afebrile, icteric, not pale, dehydrated with no pitting pedal oedema. Abdominal examination revealed an abdomen that was tender at the right hypochondrium and no clinically demonstrable ascites or palpably enlarged abdominal organs. His pulse was 106/minute and blood pressure was $100 / 70 \mathrm{mmHg}$. Other systems were normal.

Random blood glucose (RBG) at presentation was Hi (laboratory value of RBG was $816 \mathrm{mg} / \mathrm{dl}$ ), full blood count showed PCV of $39 \%$ with polymorphonuclear leucocytosis. His HbA1c was $10.8 \%$. Results of other laboratory investigations included an abdominal ultrasound that showed alcalculous, fulminant cholecystitis with gas in the lumen of the gall bladder, dyslipidaemia but normal kidney and liver functions.

An assessment of acute, fulminant cholecystitis precipitating DKA was strongly considered but patient was so acutely ill that emergency cholecystectomy was kept in view (by the surgeons) while the medical team tried to stabilize him with rehydration, correction of electrolyte imbalance and empirical antibiotics (iv ciprofloxacin $200 \mathrm{mg} 12$ hourly, iv ceftriaxone $1 \mathrm{gm} 12$ hourly, iv metronidazole 500mg 8 hourly and nil per mouth). He passed on less than 24 hours after developing signs of peritonitis.

\section{Discussion}

DM is characterized by chronic hyperglycaemia due to disorders of insulin secretion, action or both; hyperglycaemia and acidemia worsen impairments in humoral immunity and polymorphonuclear leukocytes and lymphocytes functions resulting in increased susceptibility of persons living with DM to bacterial infections ${ }^{12}$. While the first index patient in this report had chronic poor glycemic control as suggested by his HbAlc, the second index case had severe hyperglycaemia and metabolic acidosis from DKA.

Skin over the foot is prone to ulcer formation and secondary bacterial infections than other parts of the body. This is because presence of cracks on the foot during the dry weather, foot deformities and injuries from foot-wears and environmental agents such as sticks, stones, pins, needles etc predispose the foot to ulcers which subsequently get infected by bacteria. Secondly, atherosclerotic vascular compromise and sensory dysfunction (from peripheral neuropathy) are other factors making the skin over the foot more vulnerable to bacterial infections than other parts of the body. One can then appreciate why back cellulitis and abscesses are rarely reported in medical literature. Other factors besides hyperglycaemia which may predispose a person living with diabetes to develop cellulitis/abscess in the upper back around the thoracic spine area are not clear.

In their case report, the back abscess reported by Shizuma $\mathrm{T}$ et $\mathrm{al}^{13}$ in Japan was associated with DKA unlike in the index case where there was no associated DKA. Severe bacterial infection is a precipitant of DKA, an acute complication of DM, which in turn worsens the bacterial infection via hyperglycemia and acidemia (metabolic acidosis). It is worth noting that poor glycaemic control in T2DM patients is common and is usually due to lack of adherence to lifestyles and oral antidiabetic medications.

In another published literature ${ }^{14}$ by Joshi et al, bacteria implicated in skin and soft tissues infection in DM patients were classified into two: (1) mixed infection of gram negative bacilli and anaerobes or (2) gram positive cocci such as staphylococcus aureus and hemolytic streptococci. Staphylococcus aureus is, in most cases, the bacteria that causes abscess in DM patients who are less able to defend themselves against it ${ }^{15-17}$. In the first case we reported, staphylococcus aureus was the bacteria isolated. 
Emphysematous cholecystitis ${ }^{18}$, the fulminant variant of cholecystitis, is common in older patients who have diabetes mellitus; three times more in males than females and is associated with a mortality of $15-25 \%$. The second index case met these conditions despite not previously being diagnosed with diabetes mellitus. Microorganisms ${ }^{19}$ that have been isolated in patients with emphysematous cholecystitis include: clostridia, klebsiella, Escherichia coli, Enterococci and anaerobic streptococci. These are usually isolated after the emergency cholecystectomy which is usually the definitive treatment for the condition. Our patient was so ill that he did not have surgery (cholecystectomy) and the organism(s) implicated in his condition was (were) not isolated.

Gall bladder ischemia ${ }^{20}$ due to vascular compromise of the cystic artery has been recognized as the initiating factor in the development of emphysematous cholecystitis. With ischemia and necrosis of the gall bladder wall, secondary bacterial infection with gas forming organisms lead to gas production which is located in the lumen, wall of the gall bladder and or in tissues around the gallbladder. It is important to note that symptoms of emphysematous cholecystitis (right upper abdominal pain, fever, nausea/vomiting) may be trivial in patients with background diabetes or renal failure. Such patient's condition may deteriorate soon to sepsis and shock. Signs of acute peritonitis usually suggest perforation of the gall bladder.

Diagnostic tests ${ }^{18}$ for emphysematous cholecystitis include abdominal ultrasound which has high specificity for detecting gas in the gall bladder wall but low sensitivity, contrast enhanced abdominal CT scan which confirms presence of gas in the gall bladder wall or lumen, blood count which shows leucocytosis and liver function tests which may be normal. Diagnosis of fulminant cholecystitis made in the second index patient was based on the clinical features and abdominal ultrasound findings. Diagnosis was not confirmed with a contrast enhanced abdominal CT scan.
Complications $^{18}$ of emphysematous cholecystitis include septic shock, cardiovascular collapse, perforation, peritonitis and death. This is probably what happened with our second patient who did not have the benefit of an emergency cholecystectomy. In the two cases reported, chronic hyperglycaemia from background diabetes mellitus provided an environment that favored the growth of the infecting bacteria.

\section{Conclusion}

Some persons living with diabetes are not diagnosed, thus, making universal screening for T2DM imperative. Surgical intervention, good glycaemic control and wise use of antibacterial agents are indicated for favourable outcome in skin and soft tissue bacterial infections of persons living with diabetes.

\section{Reference}

1. Brownlee M, Aiello LP, Cooper ME, Vinik AI, Nesto RW, Boulton AJM. Complications of Diabetes Mellitus. In: Kronenberg HM, Melmed S, Polonsky KS, Larsen PR, editors, Williams Textbook of Endocrinology, 11th ed. Philadelphia: Saunders; 2008; 30: 1329 - 1416.

2. Rheeder P. Type 2 Diabetes: the emerging epidemic. South African Family Practice 2006; 48 (10): 20.

3. International Diabetes Federation, IDF diabetes atlas. Epidemiology of diabetes. Available at: http//www.idf.org/diabetesatlas/5e/thegllobal- burden- United States. Accessed 17 November 2013.

4. Eugene Sogwi, diabetes in sub saharan Africans and Africans In: Wass JAH, Stewart PM, Amiel SA, Davies MJ, editors, Oxford textbook of Endocrinology and Diabetes. 2nd ed. Oxford: Oxford university press; 2011: 2095 - 2143.

5. Kitabchi AE, Nyenwe E. Hyperglycaemic crises in adult patients with diabetes mellitus. In: Wass JAH, Stewart PM, Amiel SA, Davies MJ, editors.Oxford 
textbook of Endocrinology and Diabetes. 2nd ed. Oxford: Oxford university press; 2011: 2095 - 2143.

6. Uloko AE, Adeniyi AF, Abubakar LY, Yusuf SM, Abdu A, Gezawa ID, Uloko AT. Pattern of diabetes admissions in a Northern Nigerian Tertiary Health Centre.Nigerian Endocrine Practice. 2013;7(1):15 - 20.

7. Wilson J, Guy R, Elgohari S, Sheridan E, Davies J, et al. Trends in sources of methicillin-resistant Staphylococcus aureus (MRSA) bacteraemia: data from the national mandatory surveillance of MRSA bacteraemia in England, 2006-2009. J Hosp Infect. 2011; 79: 211-217.

8. Sreeramoju P, Porbandarwalla NS, Arango J, Latham K, Dent DL, et al. Recurrent skin and soft tissue infections due to methicillin-resistant Staphylococcus aureus requiring operative debridement. Am J Surg. 2011; 201: 216-220.

9. Bhavan KP, Marshcall J, Olsen MA, Fraser VJ, Wright NM, et al. The epidemiology of hematogenous vertebral osteomyelitis: a cohort study in a tertiary care hospital. BMC Infect Dis. 2010; 10: 158.

10. Aragon-Sanchez J, Quintana-Marrero Y, Lazaro-Martinez JL, Hernández-Herrero MJ, García-Morales E, et al. Necrotizing soft-tissue infections in the feet of patients with diabetes: outcome of surgical treatment and factors associated with limb loss and mortality. Int J Lower Extremity Wounds. 2009; 8: 141-146.

11. Clement S, Braithwaite SS, Magee MF, Ahmann A, Smith EP, Schafer RG, et al. Management of diabetes and hyperglycemia in hospitals. Diabetes Care. 2004 Feb. 27(2):553-91.

12. Delamaire M, Maugendre D, Moreno M, Le Goff MC, Allannic H, Genetet B. Impaired leucocyte functions in diabetic patients. Diabet Med. 1997 Jan. 14(1):2934.

13. Shizuma T, Fukui S, Todoroki K. A Case of Back Abscess and Diabetic Ketoacidosis in a Patient with Type 2 Diabetes Mellitus. Diabetes Case Rep. 2016; 1:106.

14. Joshi N, Caputo GM, Weitekamp MR, Kar chmer AW. Infections in patients with diabetes mellitus. N Engl J Med. 1999; 341: 1906-1912.

15. Takaoka S, Yamane Y, Nishiki M, Kato Y. A case of back abscess followed by ketoacidosis, elevated pancreatic enzyme and sepsis in a patient with type 2 diabetes mellitus. Practice. 2003; 20: 467-470

16. Sumi D, Kobayashi Y, Yano T, Tanito K, Kamide R. Back abscess.Practical Dermatology. 2007; 30: 881-884.

17. Rayfield EJ, Ault MJ, Keusch GT, Brothers MJ, Nechemias C, et al. Infection and diabetes: the case for glucose control. Am J Med. 1982; 72: 439-450.

18. Abengowe CU, McManamon PJ. Acute emphysematous cholecystitis. Canadian Medical Association journal, 1974; 16

19. Rosenberg AA, Cherry-Bukowiec JR, Li SH, Napolitano LM. Emphysematous cholecystitis. Surgical infections, 2013 Oct [PubMed]

20. Liao CY, Tsai CC, Kuo WH, Ben RJ, Lin $\mathrm{HC}$, Lee CC, Su KJ, Wang HE, Wang CC, Chen IH, Chien ST,Tsai MK, Emphysematous cholecystitis presenting as gas-forming liver abscess and pneumoperitoneum in a dialysis patient: a case report and review of the literature. BMC nephrology, 2016 Mar 1 [PubMed]. 